\title{
Cambridge social ontology: an interview with Tony Lawson
}

TONY LAWSON (born in Minehead, UK) is a trained mathematician located in the Faculty of Economics at Cambridge University. His work spreads over various fields, but it focuses primarily in the philosophy of social sciences, in particular: social ontology. Amongst his publications are the Routledge monographs Economics and reality (1997) and Reorienting economics (2003). Numerous journal symposia and publications by others have been devoted to his work, most recently Edward Fullbrook's Ontology and economics: Tony Lawson and his critics (2009).

Lawson's various activities over the last twenty five years include founding and chairing the Cambridge Realist Workshop and the Cambridge Social Ontology Group and serving as the director of the Cambridge Centre for Gender Studies. He is an editor of the Cambridge Journal of Economics and a member and trustee of the associated Cambridge Political Economy Society. Outside Cambridge, Lawson is a joint founder of the European Association for Evolutionary Political Economy and a founding member and trustee of the Centre for Critical Realism. He also is the primary instigator of the International Association for Critical Realism. He sits on the editorial boards of numerous international journals including Feminist Economics.

EJPE is very pleased to present this interview with Tony Lawson in which he discusses his work on various issues including social ontology and critical realism in economics, along with the differences that he perceives between his position and those of Uskali Mäki and Nancy Cartwright. We had the opportunity to sit down and talk with Lawson about all theses issues following his presentation this past spring at the research seminar series at the Erasmus Institute for Philosophy and Economics (EIPE), in Rotterdam.

EJPE's NoTE: This interview was conducted by Clemens Hirsch and C. Tyler DesRoches. Hirsch is a PhD candidate at the Erasmus Institute for Philosophy and Economics (EIPE) at Erasmus University Rotterdam. DesRoches is a $\mathrm{PhD}$ student in the Philosophy Department at the University of British Columbia, and a co-editor of the Erasmus Journal for Philosophy and Economics. 
EJPE: Perhaps you can begin by providing us with some background. As far as we know, you are a mathematician by training. How did you become interested in philosophical issues regarding economics, and in realism in particular?

TONY LAWSON: Yes, you are right; my training is mathematics, pure mathematics. The intermediate step was politics, student politics. I became involved in student politics in London. I became quite active. But I found the jargon of economists a barrier to constructive discussion. So instead of taking up a PhD place in mathematics as I had intended, I pursued economics at the graduate level.

Once in an economics faculty-I studied for a Master's degree at the LSE-I was immediately struck by the use of formalistic models which seemed to me to be very silly. These models were advanced, then as now, by people who, I think it is fair to say, are rather pedestrian in their approach to, and often very poor at, mathematics, though seemingly in awe of it, or perhaps in awe of mathematicians.

I asked numerous economists: why are you pursuing formalism if doing so seems to force you to resort to making all these irrelevant assumptions? What is the point? What is the value of it all? The only reasonable response I received was that it was hoped that the models would improve with time. Economists then, as now, seemed to be mostly unaware that there are limits to the uses of any specific form of mathematics. It was at this point, in effect, that I started to become interested in ontology, though I did not know the term. But I became very aware of the gap that often existed between the world-view presupposed by the methods used, and our best accounts of, or certainly my own intuitions about, the nature of social reality.

I moved on to Cambridge to study for a $\mathrm{PhD}$. This was the mid1970s. Here I discussed these sorts of issues with fellow research students in particular. I remember that my concerns about the irrelevance of formalistic methods were met at one point by the assertion that contemporary thinking reveals that all methods fail to facilitate insight into social reality anyway. So formalism was on par with all other methods. I was then encouraged to read more Wittgenstein and 'up-to-date' post-modernist philosophy.

In the course of these discussions I came to recognise that the position I held was that of a philosophical realist. I was never convinced that I should give up on the idea that there is a world out there and that we do get to know it under some descriptions. I decided to spend a year 
or so trying to work out whether the orientation I adopted really was so old fashioned, and whether that mattered. I wanted to explore the limitations of my intuitions. As I say, I was not convinced by any argument I found against realism. But a process that I had anticipated constituting a one-year project turned out to be an aspect of my activities that lasted for the rest of my life-so far.

\section{Was this around the time you came across Roy Bhaskar's work?}

No, not at all. That came many years later. I produced stuff criticising economics from an explicitly realist perspective for ten years or so before coming across Roy. At some point, I discovered that a number of us were making similar or anyway related critiques of current social scientific practice, but situated in different disciplines. Margaret Archer was doing it in sociology; Andrew Sayer in human geography, and so on. Roy was doing a similar thing in philosophy and had the philosophical language. Eventually, we all sort of came together picking up especially on Bhaskar's philosophical language-and the rest of his contribution, of course.

\section{Before discovering Bhaskar's realism, which account of realism were you most drawn to?}

I don't know. I didn't really know where I was headed. I just read anyone and everyone. I read quite a bit of Aristotle, Marx, Hegel, Kant, Hume, Whitehead-and many others. I also read people like Bas van Fraassen. I remember trying to make sense of his version of realism as an aid to finding the most charitable interpretation I could of what econometricians were doing. Ultimately, though, I found I had to provide my own.

My concern has long been ontological realism. But I did not get to ontology by way of reading texts on ontology or philosophical realism. Without using the category, I was focusing on ontological issues from very early on. As I said, when I first came into economics at the LSE, my basic concern was that the methods we were taught presupposed a world of a sort very different to the one in which we actually seem to live. I was asking why aren't we looking at the nature of the phenomena to begin with, or anyway at some stage in the analytical process, and I was questioning whether our methods are appropriate to the sort of reality being addressed. In that sense ontology was always my concern. 
You are commonly perceived as a 'critical realist'-by many, as the leading critical realist in economics. However, in your talk yesterday it was surprising to hear that you seem to be distancing yourself from critical realism. Is this perception correct?

No, I do not at all distance myself from critical realism. What I stress is that my primary concern is ontology, a form of study, not any set of results. Critical realism, if always evolving, remains the best selfconsciously ontological account or theory of which I am aware, but my primary interest is ontology itself, the study of the structure of the nature of reality. If you were to convince me that critical realism, or an aspect of it, is critically flawed, and showed me something more sustainable, I would be very happy about it. It is not specific results that matter to me as much as relevance. And of specific relevance to social understanding at this point, I remain convinced, is ontology. My project is characterised by a turn to ontology in social theory as an explicit undertaking. This is what I have been doing since the late 1970s.

So I am actually very happy to be perceived as a critical realist. It is not at all a misinterpretation. But it is important to see this project as multifaceted and continuously evolving. And it is also variously interpreted. You mentioned critical realism in terms of economics, but critical realism has now taken on so many forms in so many disciplines. The emphasis and presentation vary depending on where you go. So incidentally does its reception. Critical realism in some disciplines, say in human geography, is almost mainstream. It is big too in sociology and critical management studies.

I am lucky enough to be invited to give talks to groups in various disciplines and communities, and in some places I am treated like this is where it is all happening; in other places though I am treated like I am doing something really subversive. Of course, given the dire state of modern economics subversion here is indeed the goal. Some like to represent critical realism as comprising various different turns: the dialectical turn, the spiritual turn, and so on. I do not find this especially helpful. The point though is that the more that this variety occurs, and the more my own thinking evolves, the more I find that clarity is best served by elaborating precisely what I am saying at any given point rather than arguing that the results achieved are part of critical realism. 
You emphasise that your main concern is ontology as a form of study. How do you see the relationship between ontology and methodology in economics, broadly speaking?

Of course it depends on what we mean by methodology. If you mean the study of methods, all methods have their ontological presuppositions. So it is possible to examine the methods of economists and others, and a lot of my time has been spent doing that, to uncover the kind, I emphasise 'kind', of reality they are in effect presupposing.

If instead we elaborate a general social ontology, an account of social reality-should that be possible-this can inform substantive theory and choice of method. But it does not directly support any specific theory or method. To go from ontology to theory or method requires additional empirical assessments. Any two people agreeing on a particular ontological conception can differ in their additional empirical claims. But ontological insight helps avoid inappropriate reductionist stances and aids explanatory and ethical work. This is a very long story. ${ }^{1}$

Does the use of a hammer presuppose a nail? I do not know if all methods presuppose a strict ontology.

That is right, they do not. That is why I emphasise the kind of reality presupposed by given methods, and the like. The hammer does not presuppose a nail in particular, but, qua hammer, it does presuppose something that needs to be met with a specific kind of force, and, if the intention is not to break the object, then it presupposes something that can withstand the sort of force that can be exerted with a hammer. Certainly, if I say I urgently need a hammer, you can infer that the immediate task before me, i.e., the task for which I am intending to use it, is not to write a book, cut the hedge, clean the window, and so forth.

Your question gets at an important point. There is no isomorphism between ontological claims and either method or substantive theory. It is important to be clear-I do try to be. Thus I argue the sorts of formalistic methods that mainstream economists insist upon presuppose the occurrence of event regularities. But the latter is a kind of reality; I am not too specific. Regularities can be actual or fictitious, stochastic or deterministic, and so on. In addition, when I argue that economists tend to construct theories in terms of isolated systems of atoms, I usually insist that, although this conception tends to be

\footnotetext{
${ }^{1}$ Though see chapters 2, 4, and 5, of my Reorienting economics (Lawson 2003).
} 
adopted as one that guarantees an event regularity formulation, it is not a necessary condition. An event regularity could come about purely by chance, underpinned by a different causal mechanism on each occasion. Of course, the latter is unlikely and economists do hope to be more systematic in their theorising. But whilst a construction in terms of isolated systems of atoms is only sufficient, not necessary, to guarantee an event regularity, I do observe that a posteriori this is how economists mostly, in fact, proceed.

You often stress that your argument is an ontological one. However, you have also emphasised the importance of explanation as an epistemic goal in economics (Lawson 2003, chapter 4). Can you elaborate on the implications that ontology has for explanatory goals in economics?

Ontology per se cannot be expected to provide any necessary implications in terms of a precise explanatory procedure. But it can provide insight. For example, the ontological conception I defend finds that reality, natural and social, is structured: there are different ontological levels. It follows that the phenomena at any one level may be caused by, and so warrant explanation in terms of, phenomena lying at a deeper level. Certainly, it cautions against assuming a priori that all causes lie at the surface, that events are caused only by other events. But what exactly is the case in any context requires investigation. An orientation, though, is indicated. Ontological results point to the sorts of conditions that methods must be designed to be consistent with. I have argued many times, for example, that methods that presuppose closed systems are unlikely to be generally useful for helping economists understand open systems.

Having said all that, I have spent some time elaborating a dialectical approach that can be called contrast explanation, or, as I prefer, the method of explaining critical contrasts. Why? I have done so, in part at least, as a strategic move. An initial response to my setting out the ontological conception I defend was the suggestion that, because reality is portrayed as so complex, all method is limited and must knowingly distort. Therefore, it was frequently concluded, mathematical modelling in economics is no less relevant than any other approach. Of course it does not follow that just because reality is complex our analyses of it must knowingly distort. But in emphasising this I felt that the onus was on me to indicate examples of explanatory method that does not 
knowingly distort under the conditions in which we live, or as described by the ontological conception I defend, and to give some illustrations. This I have done using the method in question (see, for example, Lawson 2009a). As it happens I have found that this dialectical approach, if abstractly formulated, seems to encompass most other explanatory procedures as special cases. But that is a discovery, not a requirement. So I have engaged in explanatory illustration. But I have always emphasised that it is merely illustration. Of course that has not prevented some critics from mistakenly, and perhaps wilfully, interpreting me otherwise.

Many economists claim to be interested only in the predictive success of their theories and models, and not in establishing a 'deeper level' causal explanation. It seems that you are trying to re-direct economists away from prediction and towards epistemic activities they may not be interested in. Is this the case?

Yes, well this is where the analysis of social reality leads me. It is not an a priori orientation that I adopt. It is not that I am somehow against prediction. I think that if forty years of econometrics has revealed anything of value to us it is that you cannot very often make successful predictions of the sort that economists seek. Despite the claims of some econometricians, most results they achieve are pretty useless. Anyone can run millions of regressions with a set of data and report a result that seems to pass all tests-though the fact that millions of regressions are run means that most of the conditions of the tests are violated. But even with such results we find that as soon as new data come along the previously reported results or models typically break-down. What I am saying is that no matter how interested in successful prediction some economists may be, this interest does not make it feasible. Even so, I believe that though we cannot obtain what so many economists clearly want, we can nevertheless often get what we need; at least this is so if ultimately the underlying goal is to provide insight of a sort that enables us to contribute to making the world a better place, which I suspect it ought to be.

I have been concerned both to explain the predictive failure of economics and to come up with a conception that enables us to see exactly what we can achieve analytically. As it happens I find that we can achieve rather a lot, which ordinary people do every day anyway. Fundamentally I believe that we can make our own history. We can grasp 
the structures of reality and we-the community at large-can intentionally transform them in part according to our own goals. The future is not predetermined. So as I say we can make our own history. My arguments have driven me to this conclusion, and it is a conclusion that I am happy with. What more do we need-other than wisdom, of course, to direct our history making?

Actually, let me add that I believe the emphasis on prediction in $a$ world that is clearly open, is ultimately an aberrant form of behaviour that itself requires an explanation, probably a psychological one. In fact I am quite susceptible to the suggestion that, in many cases, the overconcern with prediction is something of a coping mechanism resulting from earlier traumas in life. But that is another story.

On several occasions you are warning against an 'epistemic fallacy' in methodological debates in economics by which you mean "the view that questions about being can always be reduced to questions about our knowledge (of being), that matters of ontology can always be translated into epistemological terms" (Lawson 2003, 111). How would you respond to an argument that your focus on ontology, might fall victim to committing an 'ontological fallacy', i.e., that it tends to reduce questions of epistemology to questions of ontology?

Well, I hope not. This takes us back to your question about the hammer. Both reductions are to be avoided. It is in order to reduce the risk of the ontological fallacy that I often go on and on about the importance of not interpreting substantive theories or methods as critical realist ones (see, for example, Fullbrook 2009, chapter 4). Any two individuals starting from a shared ontological conception can end up with a different theory of phenomenon $X$ or find themselves investigating it in different ways. Also substantive theories held as true at a moment in time can be revised in due course, with new experiences, without necessarily revising the ontological conception informing the analysis. All such possibilities depend on avoiding the ontological fallacy.

An important conceptual distinction in your account of ontology is the one between "philosophical ontology" on the one hand and "scientific ontology" on the other (Lawson 2004). Can you elaborate on this distinction?

Yes, though it should be noted that I do revise these concepts all of the time. But briefly, I have tended to use the category philosophical 
ontology to refer to the practice of seeking to uncover shared properties of phenomena of a given domain, whilst I use the category scientific ontology to explore the specifics of a phenomenon in a domain. Thus if we focus on the social domain, under the heading of philosophical ontology, I have tended to argue that social phenomena are, for example, all produced, reproduced, or transformed through practice, and are inherently relational, structured, emergent, and meaningful, etc. Under the heading of scientific ontology I have explored the differentiating features of money, gender, institutions, technology, and so forth.

\section{Philosophical ontology is an enterprise that many philosophers of science reject. How do you see it as a justifiable enterprise?}

It is not just philosophical ontology that gets rejected. Pretty much any form of social ontology is rejected by many. And there is a strand of twentieth-century philosophy, inspired by Kant, and associated with the likes of Carnap, Putnam, and Strawson, that goes further. This strand conceives all ontology as properly concerned not with any external world in itself but only with human concepts, languages, or systems of beliefs. According to defenders of this position, the most that can be undertaken is a study of the presuppositions, or ontological commitments, of specific theories or systems of belief, an activity termed 'internal metaphysics'.

But I guess you are thinking of the later Quine, or those perhaps influenced by him, who are prepared to accept certain theoretical claims as reliable and so commit to the reliability of the posited ontology as well. However, such reliability is attributed only to some very special forms of reasoning, and in effect is confined to parts of natural science. The presumption here is that it is only our best natural scientific theories that are successful in providing insight. And because these theories are about specific causal mechanisms and the like the insight provided relates only to the subject matter of what I am calling (natural) scientific ontology.

If we are forced to start from substantive theories regarded as reliable, then Quine and the others seem to be right. Certainly, the substantive theories of social science are mostly contested. And in the case of economics they are mostly simply irrelevant. However, in seeking reliable, and recognised-as-reliable, entry points we are not constrained to consider, with Quine, merely the content of theories. We 
can, for example, just as legitimately commence from any feature of experience regarded as adequate to the relevant domain of reality, including those concerning human practices. I myself have certainly used every day and scientific practices as entry points for ontological analyses.

And if philosophical ontology aims, as it does, at generalised insights we can seek reliable conceptions of human practices and so forth that too are reasonably generalised. We can do this starting both with practices whose (generalised) conditions of possibility are the subject of (non-social) natural ontology, and equally with practices whose conditions of possibility are the subject of social ontology.

This is a long story, set out for example in chapter 2 of Reorienting economics (Lawson 2003), or in a position paper downloadable from the Cambridge Social Ontology Group website (Lawson 2004). What I have just said, though, should indicate why, in contrast to many philosophers, I do indeed believe justified (non-dogmatic and nontranscendent) philosophical ontology to be possible. Indeed, it is something I take myself to have been doing.

In a recent article your position on the scope of ontology has been compared to that of Nancy Cartwright (Pratten 2007). Another recent article compares your realism to Uskali Mäki's work (Hodge 2008). What common ground and divergences do you see between your position and those held by Cartwright and Mäki?

I am certainly an admirer of the contributions of these two. We are all realists and we all-Mäki, Cartwright, and I-self-consciously present ourselves as such. The most obvious research-guiding commonality, perhaps, is that we do all look at the ontological presuppositions of economics or economists. Cartwright has questioned what the world would be like for econometrics to work, and Mäki has looked into the presuppositions of Austrian economists amongst numerous others. I have looked at mainstream modelling, Keynes, Veblen, and Hayek and others in this regard. So, yes, a common ground is an interest in examining ontological presuppositions.

Where we part company, I believe, is that I want to go much further. I guess I would see their work as primarily analytical and my own as more critically constructive or dialectical. My goal is less the clarification of what economists are doing and presupposing as seeking to change the orientation of modern economics. Or perhaps I am just more overt 
in the latter. So I come across as far more critical. Indeed I am. Specifically, I have been much more prepared than the other two to criticise the ontological presuppositions of economists-at least publically. I think Mäki is probably the most guarded. I think too he is the least critical, at least of the state of modern economics. Cartwright can be critical. I find her to be more forthcoming in presentations than when she comes to writing things up for publication. Probably most people are, myself included. But the difference between Cartwright's presentational and written styles seems more significant. Maybe this is a sensible strategy.

As you have noted, a central part of my work is philosophical and scientific social ontology. This of course relates to what I have just said. My goal is to reorient social theory. I seek to develop an explicit account of the nature of social reality. The other two do not seem to go there too much. I do not think they put forward theories of the constitution of society-or at least not very often. On these issues, I think that my own stuff connects more closely with that of the likes of John Searle. But where there are overlaps of concerns in the contributions of myself, Mäki, and Cartwright, I am not sure there is that much difference in the sorts of positions taken.

One feature of Mäki's work that I am not overly convinced by, but which he seems to value, is his method of theoretical isolation (Mäki 1992). If he is advocating it as a method for social scientific research, I doubt it will be found to have much relevance-for reasons I discuss in Economics and reality (Lawson 1997). But if he is just saying that the most charitable way of interpreting mainstream economists is that they are acting on this method, then fine. Sometimes, though, he seems to imply more. Otherwise there is not too much to divide us, I think, in terms of results.

The big differences are our goals and orientations. But these of course do shape the scope and nature of the projects pursued. For example, I cannot get enthused by Mäki's concern to see what can be justified in contemporary formalistic modelling endeavours. The insights, where they exist, seem so obvious, circumscribed, and tagged on anyway. So our actual contributions do end up being very different, which is probably good. I for one, though, would be happy if there was more communication between us all, though somehow I doubt it will happen. 
One apparent difference between you and Mäki regarding ontology is the distinction between 'bottom-up' and 'top-down' approaches to ontological theorising. Mäki regards his own approach as the former and there is evidence to suggest that he would likely describe yours as the latter (Mäki 2005; Hands 2001). Do you agree? How do you see your approach?

I do think Mäki gets this very wrong. He places in opposition what he calls 'bottom-up' and 'top-down' approaches-the former developing philosophical insight by starting from concrete economic analyses, the latter imposing onto economics philosophical injunctions determined outside of economics-and, as you note, he associates the former with himself and the latter with me. He is wrong, and possibly mischievous, in the way he characterises me, and I think it is misleading, or unhelpful, to present the options in such a dichotomous fashion.

As I view things, anyway, a real difference between Mäki and me is that he is far less, or less openly, critical of the state and practices of modern economics, as I noted just now. And this bears on our research strategies. In seeking to draw philosophical insight from modern economics Mäki seems more inclined to accept mainstream economic contributions as largely successful, or anyway uncritically. I certainly do not think we can accept mainstream contributions as successful, and so I proceed somewhat differently.

In my own stuff, as I earlier touched on when discussing the possibility of social ontology, I have preferred to start out from the everyday practices of lay people. These include, for example, those practices in which lay people negotiate: markets, institutions, and ever present social relations. These practices, I believe, are (and are recognised as being) reasonably successful. Thus I have questioned what is presupposed by the widespread everyday practices of all of us, what the social world must be like given them. ${ }^{2}$

So if there is a difference here it is that Mäki more often starts out from mainstream academic economic analyses accepted rather uncritically, whilst I prefer to start from those everyday practices widely regarded as successful. It seems to me, though, that the two approaches are equally 'bottom-up', just different.

But, as I say, I also think the dichotomy of 'bottom-up' and 'topdown' is not too helpful. There is no harm, and often great value, in

\footnotetext{
${ }^{2}$ See, especially, chapter 2 of Reorienting economics (Lawson 2003).
} 
examining the contributions of other disciplines, which I also do. Nor must borrowing or abducting insights from one field to another be harmful or misleading. Problems only arise if the results of one discipline are imposed onto a second discipline. If instead the question is posed: does this insight from that field, say philosophy or biology or wherever, have any relevance to economics, then, as long as the theorist is prepared, if appropriate, to modify any such insight to meet the conditions of the target domain, I do not see the problem. Is it such a problem to examine whether it is possible that the study of Darwinian evolutionary processes can yield insights for social analysis? As it happens my own answer to this latter question is given in Reorienting economics (Lawson 2003, chapters 5, and 10). And is it necessarily problematic to ask similar questions concerning whether insights from the philosophy of natural science have relevance for the successful development of social science?

So the distinction that Mäki draws between his approach and mine is not right; nor do I believe it is especially helpful. I am pleased you asked the question. It gives me the opportunity to express a view on the matter in this forum where Mäki is clearly influential. Perhaps Mäki will think I misrepresent him in turn. I hope I do not. But if so I hope he replies.

Judging from your work, and also from what you have been saying so far, it is very clear that you reject mainstream economics. Is this a wholesale rejection or are there elements that you think should be retained?

It is a wholesale rejection. Yes! But let me quickly elaborate. What I take to be essential to mainstream economics is the insistence that methods of mathematical modelling be everywhere and always employed in economic analysis. I emphasise the word 'insistence'. It is this insistence that I reject wholesale. I do not, of course, oppose economists using or experimenting with mathematical methods, though I am pessimistic about the likelihood of much insight being so gained. But I am opposed to the insistence that we must all use these, and only these, methods, that the use of these methods constitutes proper economics, that employment and promotion be restricted to those who use only mathematical models, that only modelling methods be taught to students, and so on. This though is unfortunately the current state of economics. The mainstream dominates. 
Let me add that I am of course very happy for advocates of the mainstream insistence on mathematical method to defend their case. But currently the method is imposed without argument and in the face of repeated explanatory failure. So yes, if I can emphasise that by the mainstream I mean the insistence on methods of mathematical modelling, mine is a wholesale rejection of this mainstream.

One of your main arguments against mainstream economics is that deductive-mathematical models do not accurately represent the targeted social phenomena of interest (Lawson 1997, chapters 2, 8; Lawson 2003, chapter 1). In a broader context this argument seems related to the long-lasting debate in economic methodology about the realism of assumptions of theories and models, originating from Friedman's famous essay (Friedman 1953). Can you discuss your position in this debate?

Okay, let me elaborate my position in a series of steps.

First, a starting point of my position is the widely recognised long history of failure of mathematical-deductivist modelling in economics. These methods presuppose event regularities or correlations. It has been found that these sorts of regularities rarely occur in the social realm.

Second, an additional starting point is that mathematical models are typically found to be formulated in ways that are acknowledged, even by their formulators, as being wildly unrealistic.

Third, mathematical economists, many of whom seem endlessly optimistic that success will eventually be achieved, persevere with their modelling endeavours and so seek theories that are consistent with, that guarantee, event regularity formulations. The way this is typically achieved is by their implicitly constructing theories in terms of isolated atoms. By atoms I do not mean something small. I mean factors that have the same effect, if triggered, whatever the context. It is this assumption of atomism that guarantees that if the factor is triggeredthis triggering is the first event-the same outcome, the second event, always follows, so long as nothing interferes. It is the assumption of system isolation that guarantees that nothing does interfere.

Fourth, I defend a conception of social reality-a social ontology-as an emergent realm that is: highly interrelated, with each phenomenon being constituted in relation to everything else; intrinsically dynamic or processual, being continually reproduced or transformed through 
practice; structured; and characterised by meaning, values, and much else.

Fifth, the failures and lack of realisticness of many economic contributions that constitute my starting points are easily explained if the ontological conception I defend is at all correct. For social reality is found not to comprise parts that are isolated, for more or less everything seems to be constituted in relation to other things. And components cannot be treated as atomistic or stable, for each is being continually transformed.

Hence, in producing theories couched in terms of isolated atoms that are quite at odds with social reality, modellers are actually compelled to make substantive claims that are wildly unrealistic. And because social reality does not conform to systems of isolated atoms, there is no guarantee that event regularities of the sort pursued will occur. Indeed, they are found not to. This is a long story set out, for example, in Reorienting economics (Lawson 2003, chapter 1). But the above contains the gist of my critique of the modern mainstream insistence on methods of mathematical modelling.

Now, sixth, Friedman enters this scene arguing that all we need to do is predict successfully, that this can be done even without realistic theories, and that unrealistic theories are to be preferred to realistic ones, essentially because they can usually be more parsimonious.

The first thing to note about this response is that Friedman is attempting to turn inevitable failure into a virtue. In the context of economic modelling, the need to produce formulations in terms of systems of isolated atoms, where these are not characteristic of social reality, means that unrealistic formulations are more or less unavoidable. Arguing that they are to be preferred to realistic ones in this context belies the fact that there is not a choice.

What amazed me about the initial responses to Friedman by numerous philosophers and others is that they mostly took the form: prediction is not enough, we need explanation too. Rarely, if ever, was it pointed out that because the social world is open, we cannot have successful prediction anyway.

So my own response to Friedman's intervention is that it was mostly an irrelevancy, but one that has been opportunistically grasped by some as a supposed defence of the profusion of unrealistic assumptions in economics. This would work if successful prediction were possible. But usually it is not. 
Strangely enough, perhaps, if we could have successful prediction I might be inclined to side with Friedman. If spontaneous event regularities were ubiquitous, then we could indeed use them for predictive purposes irrespective of the theory of underlying causal mechanisms associated with them. And if they were spontaneous and ubiquitous we might not be able to identify underlying causes anyway. It is our ability to manipulate the latter, or the failure of supposed certain regularities, which is often essential to uncovering underlying causes.

Anyway, I think I have said enough on this. Friedman's intervention was based on the error of supposing we can predict successfully, and is now often opportunistically referred to as a supposed justification for unrealistic models in a context in which realistic models are not a viable option and successful prediction is not achieved either.

Incidentally, Friedman's position is often advanced as an alternative to realism. That is just a mistake. Friedman is a realist about events and models, and even causal mechanisms. He has to be to assess, as he does, that certain formulations of them can be unrealistic. Only a realist can coherently claim to be, or that others are, wrong, or unrealistic, or right, or realistic, etc. It never was a realist versus non-realist debate. Every position is realist. I do not know anyone in economics who is not a realist. Some of us, though, are explicit about it. That is a major difference.

\section{What about Deirdre McCloskey?}

McCloskey is a realist about rhetoric! She is a realist about the economic profession. She is a realist about econometrics... Realism is inescapable! The question is always not whether someone is a realist, but what form that person's realism takes.

Contrary to your rejection of mainstream economics you seem to hold a quite favourable stance towards heterodox economics in general. Can you be specific? Which branches of heterodox economics do you regard as particularly promising and how do you see the role of your ontological account in relation to the various heterodox schools of thought?

I can be critical about everyone. But I think my dominant orientation, and natural inclination is to be inclusive in all walks in life. I am very critical of the mainstream because it is exclusive. It insists that only people doing just mathematical modelling should be admitted to the 
economics academy. As you know, my background is mathematics, I can do the maths. So I do not feel excluded in principle even by them; I just do not like them to exclude everyone who does not want to do maths.

So yes, most of my arguments directed towards heterodox economics are concerned with identifying commonalities. I think the heterodox groups implicitly share an ontological conception broadly along the lines I outlined a few minutes ago. These groups are differentiated from each other in focusing on different aspects. So I see them basically as divisions of labour in the same overall project, which I truly think we are.

I feel positive about aspects of most of the traditional heterodox groups. This is especially true of feminist economics, but also of old institutionalism, post Keynesianism, Marxian economics, and even Austrian economics-which seems to surprise and dismay some people. In recent years, I have probably taken most from the feminists.

But I can certainly be critical even in the context of the traditional heterodox groupings. I mean, we find all sorts of funny things going on at heterodox economics conferences. There are people there who still think that theorems are the most important thing. They are just more tolerant than the mainstream in the sense that they do not try to make everyone else do theorems. Others think that econometrics is necessary to applied work. Most strangely, perhaps, there are those that seem to think that a switch from linear to non-linear forms of mathematical modelling represents some kind of advance in terms of realisticness. Worst of all, there are those, overlapping with some of those already mentioned, who apparently believe that, so long as conclusions already thought to be correct are reached, it does not matter what methods or assumptions are employed. And there are post-modernists who think we cannot say anything much about anything. I can be critical, but I put the emphasis more on unification and commonality.

Probably the feature of the heterodox traditions of which I feel the most critical is a lack of willingness on the part of some to fundamentally question the founding contributors. People identify themselves with a certain tradition and are very resistant to anything that challenges views that they associate with their figureheads. Relatedly, there can be too much arguing from the authority of the figureheads. Any is too much. And, perhaps even worse, there is quite a lot of trying to pretend that all recent insights, including ontological ones, were first formulated by these founders, when it is often very 
obvious that such is not the case. Probably the worst of these latter tendencies are manifest in the contributions of some of those who associate with Keynes or Veblen.

What impact do you think critical realism has had so far on economics, mainstream or heterodox, and on philosophical issues pertaining to the discipline?

I do not know. I am not sure it is for me to say. Perhaps let me make one claim. I think that it has contributed significantly to the fact that ontology is now explicitly a part of the ongoing conversation. It is not really apparent in the mainstream discourse, but it is pretty much evident everywhere else in economics. This is so even amongst those methodologists who seem reluctant to criticise mainstream economics and seemingly have little interest in heterodox economics or in changing the state of modern economics. It is true even of those methodologists, mostly a subset of the latter, who apparently feel uneasy about critical realism, including those who like to pretend to themselves, or to the world, that it is not really there.

In Edward Fullbrook's introduction to his recent book (Fullbrook 2009) he points out how, at least up to the mid-1990s, the term 'ontology' almost never figured in economic methodology, or indeed anywhere else in economics. Now that has all changed. And I think those contributing to critical realism can take a good deal of the credit for this-or blame, if you feel negative about the situation.

In your view, what role does or should economics play in society? Maybe you can also discuss the role of economics, as you see it, in the current financial crisis?

My views on all this are long and complex. In brief, I think the goal of economics, and indeed social sciences more widely, should be to uncover or identify the conditions that get in the way of a society based on generalised human flourishing. Of course we are all different and everything changes, so this is a complex story. It requires lots of ontology.

The role that economics has in fact played in the current crisis, certainly academic economics, is basically a passive but negative one. By getting on with their mathematical modelling activities, as they do, economists are mostly being irrelevant, but are diverting resources that could be used to provide insight. And worse still, irrelevant 
mathematical models of the sort economists produce, have been used by investment bankers and other speculators and, perhaps most worryingly of all, by rating agencies. But this is a long story. I have set out some of my views on this in a paper that appears in the Cambridge Journal of Economics (Lawson 2009b).

Earlier in our discussion of Cartwright and Mäki you expressed a wish for more dialogue. Indeed, it seems to be the case that there is relatively little contact between critical realists and other economic methodologists who, one might argue, hold similar positions. Why do you think this is so?

I do not know if what you say is entirely true. I mean there are different forms of contact. For example, we have this workshop in Cambridge and almost everybody I can think of in economic methodology has been invited, and most have turned up.

Speaking personally, it is true that, because my engagement with methodology is in large part motivated to change things, I perhaps share more with heterodox economists interested in methodology than with the economic methodologists who do methodology more for its own sake. I think I am quite active in heterodox circles. But I am happy to engage with anyone.

As a rather boring practical matter, it is the case that I get very little money for travel. Mostly I go where people invite me and throw in the travel costs. I thus interact with whoever invites me. This also means I miss most of the big conferences. But at this moment it does mean that I am able to interact with you lot here at Rotterdam. I am sorry Mäki has moved on to Helsinki.

Of course, I interact with everyone in publications. See for example Edward Fullbrook's (2009) latest volume, or past issues of Journal of Economic Methodology (2004, vol. 11, issue 3), Feminist Economics (2003, vol. 9, issue 1), Review of Social Economy (1998, vol. 56, issue 3), Economia (1997, vol. 1, issue 2), or the volume by Fleetwood (1999), and such like. Indeed, I think I probably engage in written debate with other methodologists as much as anyone. Am I so wrong in thinking that?

Perhaps the previous question was somewhat lacking in precision. Let me try again. It seems that there is, potentially, considerable common ground between your work on ontology in economics on the one hand and work on social ontology by philosophers such as Margaret 
Gilbert, John Searle, and Raimo Tuomela on the other. You briefly mentioned Searle a few moments ago but in your published work there seems to be little interaction with these authors. Do you think there is a conflict between this work on social ontology and your ontological account?

It is certainly the case that I do not have much contact with academic philosophers, less perhaps than I should. This is mainly because I find them, by and large, to be overly analytical, more concerned with being thought to be clever than with addressing matters about the way the world is, which is my interest. By and large I find the best philosophy, or anyway that which connects most with my own interests, is done outside philosophy departments. But John Searle is fundamentally interested in the way the world is, as are the others you mention. Indeed, Searle's work on the constitution of society is ignored by many philosophers precisely because it is insufficiently like their conception of proper analytic philosophy. Searle's contributions, I think, like those of critical realism, are much more influential amongst natural and social scientists than amongst philosophers.

Actually, I did take up an invitation to visit Searle and his ontology group in Berkeley last summer, for about five weeks. In fact I went twice, because I was also earlier invited by Searle to give a talk at his bi-annual Collective Intentionality Conference, which incidentally also featured Tuomela and Gilbert. It was a very fruitful experience for me. No, I do not see a big conflict in our projects, certainly not between mine and Searle's. Searle actually thinks that we agree on just about everything. I am not so sure, but he well may be right. Certainly we agree on rather a lot. And we are very, very similar in our mentalities and orientation. Searle is very ready to speak or write his mind on anything, to say things as he sees them, no matter what the consequences in terms of unpopularity within his own discipline. I think I try to do the same.

In terms of our projects we spent a lot of time comparing notes. In fact, I led a seminar contrasting the two projects. The chief difference between us, I believe, is not the positions we sustain, but how we get there. Searle has kind of built on his theorising of language, the mind, and so forth. At all stages he has been concerned that his theories are consistent with our best conceptions in the natural sciences. The latter have acted as an explicit control on his thinking. In contrast, I have tended to start from conceptions of generalised social practices, and asked what the social world must be like for them to occur. But as I say, 
the results we reach turn out to be very similar. The categories used are sometimes different, and we present our results differently. We may differ on issues like emergence; I appear to defend a stronger form than Searle does. But actually even here the difference seems mostly to disappear once we unpack some of the terminology. So no, I do not think there is any significant conflict. None anyway that seems irreconcilable. We actually discussed the idea of joint work when we met. But I doubt we will ever find the time or opportunity to fit it in.

\section{You already mentioned the Cambridge Social Ontology Group. The group has been going strong for years now. Can you describe what it is and how it came about?}

Yes! First though it is important to distinguish the Ontology Group from the Realist Workshop. Many conflate the two. The latter is a weekly Monday night seminar, open to all. It started twenty years ago with a group of $\mathrm{PhD}$ students, each working with me on philosophical issues, who wanted to meet with each other and discuss philosophical matters. We met one Monday night. The session was successful, so at the end of the night we arranged to meet the following Monday. That led to us meeting again on the Monday following that one. And we are still going twenty years later. That is the Realist Workshop.

When we started out the Realist Workshop it was a very informal, organically developing sort of endeavour. Those who came kind of grew up together and helped each other in their research, and so forth. After about ten years or so the Realist Workshop had changed. It was still meeting on Monday nights, but it was no longer this organic group we started with where we read each others' papers. Many of the original attendees had left Cambridge to gain academic employment. And the emphasis had become less personal. It had become more another type of performance.

People come from around the world, famous people are coming in and give their talks, Nobel Memorial Prize winners like Amartya Sen or whoever. Each talk, though, is understandably usually unconnected with that of the previous week, and the audience can vary from week to week as well. It has remained a wonderful intellectual event. But en route we lost that organic character we had in the beginning. We lost the idea of developing our ideas together as a group.

That is why about ten years ago I set up the Ontology Group. It is a smaller group-of about fifteen people. The idea is that the same people 
show up each time, and there is continuity in the discussion from meeting to meeting. What we do there is basically discuss topics in ontology. The structure is variable. A topic can last for an hour, or for a term and more. We spent about a term discussing the nature of gender, even longer discussing the nature of rules. We have even discussed the nature of econometrics. As I say people are expected to come to each meeting and the discussion progresses. That is the point of the Ontology Group.

Now the Realist Workshop and the Ontology Group are both oriented more to questions than to answers, though we seek answers. In the Ontology Group in particular we explore limitations of our shared beliefs. Sometimes it almost feels like a confessional. We question and re-question everything, not least the things we defend quite strongly in public. And we do laugh a lot. We continually criticise ourselves. We also go round and round in dialectical circles, trying to make sure that everything is coherent with everything else, following every criticism and change in understanding-though we rarely succeed. No one feels the need to be protective about anything. Everyone's ego is left outside the room. It is very enjoyable and rewarding. The meetings are supposed to last two hours but usually they go on longer. When we are really keen or excited we fit in additional meetings at night times in pubs, or we may meet over vacations. As I say it is basically an ontology talk shop. But everyone involved seems to get a lot out of it.

Finally, how do you see the future development of critical realism? Where do you think it is headed? Perhaps you can also tell us a bit about your own research plans?

I do not know about the future of critical realism. Throughout the disciplines it is quite healthy. It has become a big movement now. Once a year there is the conference of the International Association for Critical Realism, an organisation I effectively set up about ten years ago, and all the disciplines are there: sociology, politics, anthropology, all the natural sciences, and all the arts too, and the humanities. Everyone is there. It is doing well.

But I do not know what the future holds. There is clearly an awful lot of ontological work still to be done-of course, there always will be. And critical realism is branching out in different directions. There might come a point where the label has outlived its usefulness. As I think I mentioned earlier, there are people who call themselves this or that sort 
of critical realist. There are all sorts of turns and there are people within critical realism who do not like this turn or that turn or another turn. So, it is much more heterogeneous than it may seem to be. The future is open. Who knows where it will all lead?

As for myself, I am working on questions like: what is the nature of money? What is the nature of this? What is the nature of that? I am also working on a theory of society that extends, but in some significant ways is quite different from, my earlier account. It is slightly more substantive, and in some ways more naturalistic, than what I have done before, and I do not know whether other critical realists will find it appealing. But that is something for the future.

\section{REFERENCES}

Fleetwood, Steven (ed.). 1999. Critical realism in economics: development and debate. London: Routledge.

Friedman, Milton. 1953. The methodology of positive economics. In Essays in positive economics, Milton Friedman. Chicago: University of Chicago Press, 3-43.

Fullbrook, Edward (ed.). 2009. Ontology and economics: Tony Lawson and his critics. London: Routledge.

Hands, D. Wade. 2001. Reflections without rules. Cambridge: Cambridge University Press.

Hodge, Duncan. 2008. Economics, realism and reality: a comparison of Mäki and Lawson. Cambridge Journal of Economics, 32 (2): 163-202.

Lawson, Tony. 1997. Economics and reality. London: Routledge.

Lawson, Tony. 2003. Reorienting economics. London: Routledge.

Lawson, Tony. 2004. A conception of ontology. Mimeo. University of Cambridge. http://www.csog.group.cam.ac.uk/A_Conception_of_Ontology.pdf (accessed June 2009).

Lawson, Tony. 2009a. Applied economics, contrast explanation and asymmetric information. Cambridge Journal of Economics, 33 (3): 405-419.

Lawson, Tony. 2009b. The current economic crisis: its nature and the course of academic economics. Cambridge Journal of Economics, 33 (4): 759-777.

Mäki, Uskali. 1992. On the method of isolation in economics. Poznan Studies in the Philosophy of the Sciences and the Humanities, 26: 319-354.

Mäki, Uskali. 2005. Reglobalising realism by going local, or (how) should our formulations of scientific realism be informed about the sciences. Erkenntnis, 63: 231-251.

Pratten, Stephen. 2007. The scope of ontological theorising. Foundations of Science, 12 (3): 235-256.

Tony Lawson's Website:

$<$ www.econ.cam.ac.uk/faculty/lawson/>

Cambridge Social Ontology Group Website:

$<$ www.csog.group.cam.ac.uk/> 